\title{
INFLUENCE OF FIELD-CAST TENSILE PROPERTIES AND TEST METHODS ON SIMULATED REINFORCED HPFRCC COMPONENT BEHAVIOR
}

\author{
MATTHEW J. BANDELT* \\ *New Jersey Institute of Technology \\ Newark, NJ USA \\ e-mail: bandelt@njit.edu
}

Key words: High-performance fiber-reinforced cement composite, Fiber orientation, Simulation

\begin{abstract}
Research efforts have recently been made to simulate the performance of reinforced highperformance fiber-reinforced cement composites (HPFRCCs) at high levels of deformation. Although constitutive models for HPFRCCs have been developed, selecting appropriate mechanical properties of HPFRCCs in simulations remains a critical aspect to predicting component response in large-scale structures. Additionally, fiber orientation and specimen size are known to significantly impact the tensile and flexural response of HPFRCCs. This paper investigates the simulated performance of reinforced HPFRCC components using tensile properties obtained through various testing and casting methods which result in different fiber orientation. An emphasis is placed on predicting reinforced HPFRCC performance at high levels of deformation, and specifically reinforcement fracture, using total-strain based material models. Recommendations are made for selecting appropriate test-methods and casting-methods for characterization specimens that can improve simulated performance of reinforced HPFRCC components.
\end{abstract}

\section{INTRODUCTION}

High-performance fiber-reinforced cementitious composites (HPFRCCs) contain randomly oriented fibers which interact with a cementitious matrix to improve the tensile ductility of the system [1]. The mechanical properties of HPFRCCs, such high material toughness and damage tolerance, have led researchers to propose their use in structural systems [2, 3, 4]. By replacing concrete with an HPFRCC material, the strength, stiffness, and displacement capacity of reinforced concrete members has been observed to increase in a variety of flexureand shear-dominated experiments under various loading conditions [5, 6, 7, 8].

Although reinforced HPFRCC components often exhibit higher strength and displacement capacity when compared to traditional concrete, research has shown that failure often occurs due to reinforcement fracture as opposed to crushing of the concrete material as is typical in reinforced concrete members [9]. A tensionstiffening effect causes deformation to localize at a single cross section once a dominant crack forms in a reinforced HPFRCC member [10]. Higher bond strengths have been observed in HPFRCC components, which limit the amount of splitting cracks that form, thereby preventing reinforcement from deforming over long debonded lengths as is observed in reinforce concrete members [11, 12].

While experimental results have shown that reinforced HPFRCCs generally improve the strength, deformation capacity, and damage tolerance of reinforced concrete systems, numerical simulation tools are needed to predict the 
behavior of alternative structural designs with HPFRCCs and how future HPFRCC materials will perform in structural members. Most computational research to date has focused on constitutive model development and application [13, 14, 15, 16], and the behavior at high deformation levels that can induce reinforcement fracture has not been thoroughly investigated. Additionally, the modeling implications of variations in observed mechanical properties from tensile specimens with different geometries [17, 18] is not under well understood.

In this paper, reinforced HPFRCC structural components are simulated and compared to experimental performance with a focus on HPFRCC mechanical properties. Numerical simulations are conducted to high deformations in order to predict deformation levels that cause reinforcement fracture. The influence of variations in mechanical properties obtained from prior research through testing specimens with various geometries [17, 18] is explored to show how HPFRCC mechanical properties impact simulated deformation capacity due to reinforcement fracture.

\section{MODEL GEOMETRY AND MATE- RIAL BEHAVIOR}

\subsection{Finite Element Model}

The geometry and boundary conditions used in the finite element model are based on experimental results from prior work by the author [9], and are shown in Figure 1. The model consists of a simply supported doubly reinforced flexural element loaded at midspan. Half of the member was modeled for computational efficiency. Eight-noded plane stress element were used to model the HPFRCC material, and twonoded truss element were used to model the longitudinal reinforcement. Four-noded interface elements were used to connect the HPFRCC and the reinforcement elements, and transverse reinforcement was modeled using embedded reinforcement elements. The following numerical integration schemes were used for the different element types: plane stress elements were integrated using a three by three Gauss integration
DOI 10.21012/FC9.189 scheme, truss elements were directly integrated, and interface elements were integrated using a two-point Newton-Coates integration scheme.

The plane stress elements were $10 \mathrm{~mm} \times 10$ $\mathrm{mm}$ in size with a thickness of $130 \mathrm{~mm}$, while the interface elements and truss elements had a length of $10 \mathrm{~mm}$. The model had a total longitudinal reinforcement area of $258 \mathrm{~mm}^{2}$ and the total reinforcement perimeter was $80 \mathrm{~mm}$. The perimeter was used for the interface elements in order to simulate bond-slip effects. The stirrups were modeled with a total area of $16 \mathrm{~mm}^{2}$.

Compression springs with a stiffness of $1.0 \times$ $10^{4} \mathrm{~N} / \mathrm{mm}$ were used at the supports to replicate the experimental conditions, and elastic plates were used at the support and loading points. A Newton-Raphson equilibrium iteration process was used in the solution of the finite element simulations. Convergence was satisfied when the force, displacement, or energy criteria were met, which were set at $1 \%, 0.1 \%$, and $0.01 \%$, respectively.

\subsection{Material Properties and Parameters}

Steel reinforcement was modeled using a Von-Mises plasticity based material model. The longitudinal reinforcing steel included isotropic strain hardening based on experimental data [9]. The modulus of elasticity was $200 \mathrm{GPa}$ with a yield stress of $455 \mathrm{MPa}$ and an ultimate strength of $675 \mathrm{MPa}$ at a strain of $18 \%$. Fracture was assumed to occur at $20 \%$ strain, which is $2 \%$ strain beyond the strain at which the ultimate stress was reached. Transverse reinforcement was modeled with a Von-Mises material model, a modulus of elasticity of $205 \mathrm{GPa}$, and a yield stress of $690 \mathrm{MPa}$. Poisson's ratio was set at 0.3 for both longitudinal and transverse reinforcement. Bond-slip effects were included in the simulations based on previous bond research on HPFRCCs [12].

The compressive response of the HPFRCC material was modeled using a parabolic curve based on compressive fracture energy [19]. The compressive fracture energy was $53 \mathrm{MPa}-$ mm with a compressive strength of $47 \mathrm{MPa}$. Young's modulus and Poisson's ratio were as- 


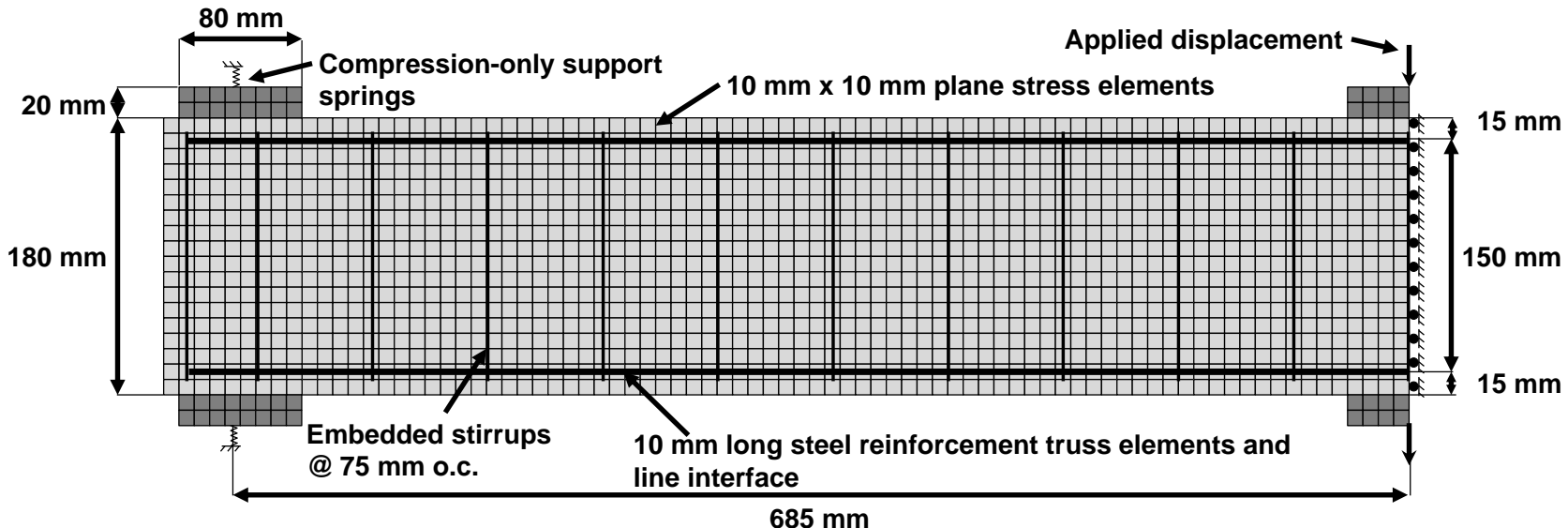

Figure 1: Finite element model geometry.

sumed to be $16 \mathrm{GPa}$ and 0.15 , respectively.

A total-strain based crack model based on fracture energy was used to model the tensile behavior of the HPFRCC material [20]. The material model utilized a multi-linear curve to describe the tensile response of the HPFRCC, and the softening behavior was modeled based on fracture energy. Four tensile-stress strain diagrams were used in the simulations, and were based on experimental tensile response from specimens with four geometries [17, 18]. The tensile properties observed through these four experiments were obtained in an Engineered Cementitious Composite (ECC) mixture containing PVA fibers at the same fiber volume fraction as the reinforced beam experiments [9, 17, 18], and are believed to represent the behavior of the larger reinforced HPFRCC member.

The tensile stress-strain information is described in Figure 2 and tensile parameters used and model names are reported in Table 1. The tensile behavior of the HPFRCC is assumed to have three segments. The first segment is assumed to be elastic until the first cracking strength is reached at a stress of $\left(\varepsilon_{1}, \sigma_{1}\right)$; the second segment has a linear branch until the point $\left(\varepsilon_{2}, \sigma_{2}\right)$ is reached; in the third segment, crack localization occurs and the material is assumed to soften linearly based on the experimentally observed fracture energy $\left(G_{f}\right)$.

The fracture energy values reported in Table 1 were calculated based on reported stressstrain properties and gage lengths used in experimental testing [17, 18]. Fracture energy was calculated by multiplying the experimental area under the softening branch of the stressstrain curve by the experimental gage length $(h)$. The final strain value $\left(\varepsilon_{3}\right)$ for the finite element model was then calculated to make the model mesh independent using Equation 1. In Equation $1, h$ is taken as square root of the area of an element, which in the case of this the 10 $\mathrm{mm} \times 10 \mathrm{~mm}$ square element is equal to 10 $\mathrm{mm}$.

$$
\varepsilon_{3}=2 \frac{G_{f}}{h} \frac{1}{\sigma_{2}}+\varepsilon_{2}
$$

The experimental stress-stain properties used to characterize the HPFRCC material represent a range of different tensile specimens including plates, dogbones and cylinders. The variations in observed tensile strength when softening begins (i.e., $\sigma_{2}$ ) range by a factor of approximately 2 , while variations in strain when softening begins (i.e., $\varepsilon_{2}$ ) differ by a factor as great as 5 . These variations are primarily due to fiber orientation, which can vary greatly based on the specimen geometry [18]. The finite element simulation results presented 
in the following sections show how these variations influence predicted component behavior and deformation capacity.

The simulation names presented in Table 1 refer to the tensile properties obtained from representative tensile experiments and include descriptions of the type of specimen, the stress when softening begins (i.e., $\sigma_{2}$ ), the strain when softening begins (i.e., $\varepsilon_{2}$ ), and the fracture energy (i.e., $G_{f}$ ). For example, the simulation named Plt-5.0-2.3-1.7 uses tensile properties obtained from a plate specimen where a tensile strength $\left(\sigma_{2}\right)$ of $5.0 \mathrm{MPa}$ was observed, a strain at softening $\left(\varepsilon_{2}\right)$ of $2.3 \%$, and a fracture energy $\left(G_{f}\right)$ of $1.7 \mathrm{MPa}-\mathrm{mm}$.

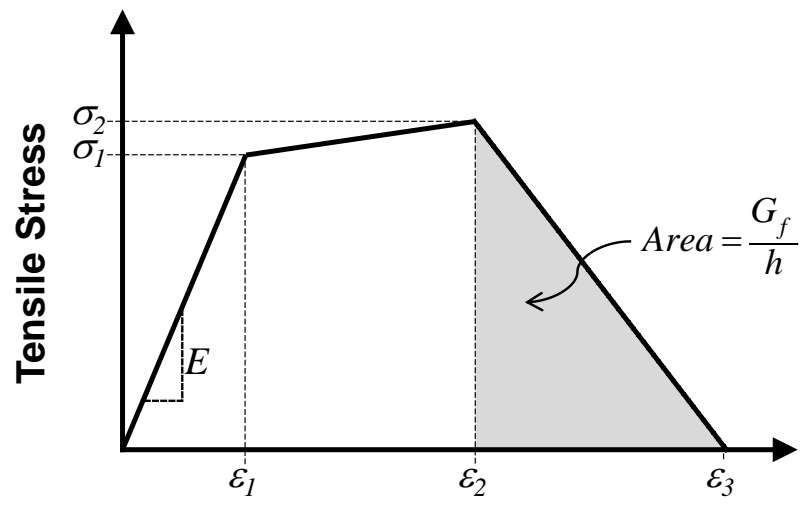

Tensile Strain

Figure 2: Tensile stress versus strain diagram.

\section{SIMULATION RESULTS}

\subsection{Initial Load-Deformation Behavior}

The initial load versus deformation behavior of the experimental and simulated responses are shown in Figure 3 where deformation is reported as the midspan vertical displacement divided by the shear-span length, which is 685 $\mathrm{mm}$. The various influences of the selected tensile strength, strain capacity, and fracture energy parameters are shown in this plot of load versus deformation.

Model Plt-5.0-2.3-1.7 had the highest tensile strength and lowest fracture energy in the simulations conducted herein. This simulation reached a strength of $81 \mathrm{kN}$ within the first $2.0 \%$ deformation level which was the highest rein-
DOI 10.21012/FC9.189 forced component strength within the first $2.0 \%$ deformation because of its high tensile strength. The member experienced a sudden drop in loadcarrying capacity at $2.2 \%$ deformation because of its low fracture energy (1.7 $\mathrm{MPa}-\mathrm{mm})$ in comparison to the other simulations which had fracture energies between 2.3 MPa-mm and 2.4 MPa-mm.

Model Dgb-4.1-1.9-2.3 had a tensile strength of 4.1 MPa which was 0.9 MPa lower than Plt5.0-2.3-1.7. As a result, this member reached a lower reinforced component strength of 76 $\mathrm{kN}$ within the first $2.0 \%$ level of deformation. In comparison to Plt-5.0-2.3-1.7, a higher deformation level was reached in Dgb-4.1-1.9-2.3 before a sudden drop in loading carrying capacity occurred at $2.8 \%$ deformation. The drop in load-carrying capacity occurred in Dgb-4.11.9-2.3 at a higher deformation level because it had a fracture energy of $2.3 \mathrm{MPa}-\mathrm{mm}$ in comparison to 1.7 MPa-mm in Model Plt-5.0-2.31.7. The higher level of fracture energy allowed the HPFRCC material in the reinforced component to carry tension to a higher level of component deformation before crack localization.

Model Plt-3.6-3.4-2.4 had the highest tensile strain capacity $(3.4 \%)$ and fracture energy (2.4 MPa-mm), and a tensile strength of $3.6 \mathrm{MPa}$, which is lower than the tensile strength of the two previously described models. Since Plt3.6-3.4-2.4 had the highest tensile strain capacity and fracture energy, it reached the highest level of deformation before a drop in load carrying capacity occurred at approximately $3.2 \%$ deformation. In terms of component strength, Plt-3.6-3.4-2.4 reached a strength of $78 \mathrm{kN}$ within the first $2.0 \%$ deformation level, which is slightly higher than Dgb-4.1-1.9-2.3 (786 $\mathrm{kN})$. The higher strength in Plt-3.6-3.4-2.4 is attributed to it's higher tensile strain capacity of $3.4 \%$ in comparison to $1.9 \%$ for Dgb-4.1-1.92.3 .

In comparison to the three other models, Cyl-2.4-0.6-2.3 had the lowest component strength of $70 \mathrm{kN}$ within the first $2.0 \%$ deformation, and also did not experience the same drop in load carrying capacity that was observed in 
Table 1: Tensile parameters for finite element simulations.

\begin{tabular}{|c|c|c|c|c|c|c|c|}
\hline Simulation & Reference & Cross & Loading & $\sigma_{1}$ & $\sigma_{2}$ & $\varepsilon_{2}$ & $G_{f}$ \\
\hline Name & Author & Section & Configuration & [MPa] & {$[\mathrm{MPa}]$} & {$[\%]$} & [MPa-mm] \\
\hline Plt-5.0-2.3-1.7 & \multirow{2}{*}{ Kanakubo et al. 17 } & $30 \mathrm{~mm}$ x $13 \mathrm{~mm}$ Plate & Pin-Fix & 3.7 & 5.0 & 2.3 & 1.7 \\
\hline Dgb-4.1-1.9-2.3 & & $100 \mathrm{~mm}$ x $60 \mathrm{~mm}$ Dogbone & Pin-Fix & 2.3 & 4.1 & 1.9 & 2.3 \\
\hline Plt-3.6-3.4-2.4 & \multirow{2}{*}{ Douglas and Billington $[18$} & $76 \mathrm{~mm}$ x $13 \mathrm{~mm}$ Plate & Fix-Fix & 3.4 & 3.6 & 3.4 & 2.4 \\
\hline Cyl-2.4-0.6-2.3 & & $\phi 100$ mm Cylinder & Fix-Fix & 3.5 & 2.4 & 0.6 & 2.3 \\
\hline
\end{tabular}

the other simulations. There was not a drop in load carrying capacity because Cyl-2.4-0.6-2.3 had the lowest tensile strength and strain capacity. The low strength and strain capacity prevented the formation of a localized crack, and therefore, a drop in load carrying capacity upon exhaustion of the tensile strength at that crack as was observed in the other simulations. This behavior was most similar to the experimental result where a drop in load carrying capacity was not observed [9] in this initial load-deformation range.

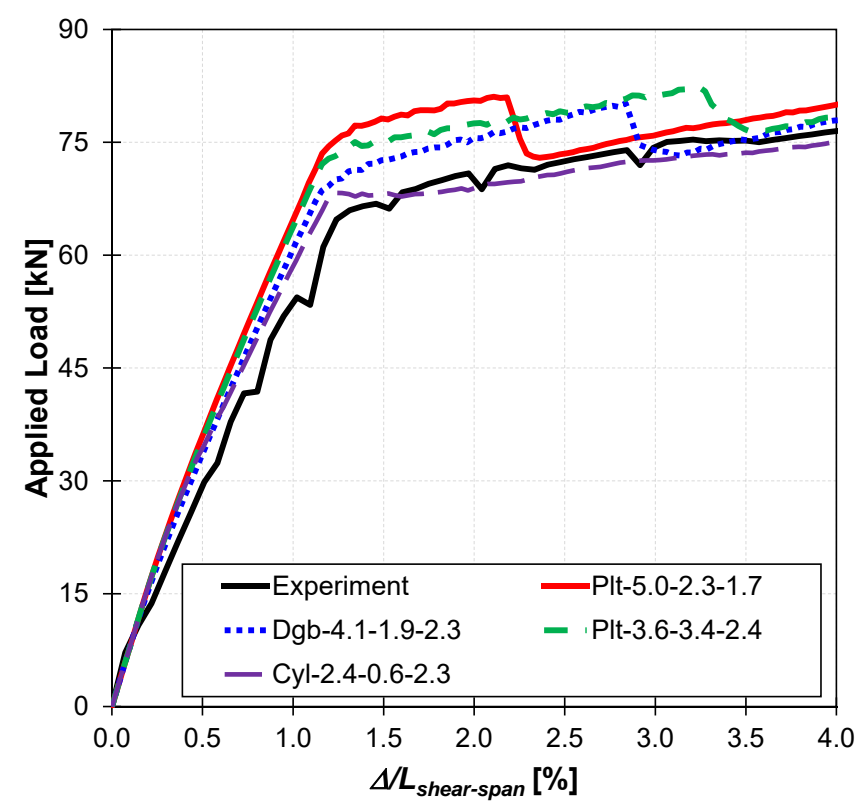

Figure 3: Initial applied load versus deformation.

\subsection{HPFRCC Damage and Simulated De- formation Capacity}

Figure 4 shows contours of principal tensile strains at deformations of $2 \%, 6 \%$ and $12 \%$ for each simulation. Locations of high principal tensile strains correspond to locations of dominant cracks. The full plots of load versus de- formation are shown in Figure 5.

In simulation Plt-5.0-2.3-1.7, a dominant crack formed at approximately $2 \%$ deformation which corresponds to the drop in load carrying capacity at $2 \%$ deformation. A second dominant crack formed at $6 \%$ deformation which corresponds to the formation of a second drop in load carrying capacity.

In simulation Dgb-4.1-1.9-2.3 a dominant crack formed between 2 and $4 \%$ deformation as shown in the load-deformation diagram, and by strain contours in Figure 4. The dominant crack formed at a higher deformation level because of the higher fracture energy of Dgb-4.1-1.9-2.3 in comparison to Plt-5.0-2.3-1.7. The response of Plt-3.6-3.4-2.4 was similar to that of Dgb4.1-1.9-2.3 in that a dominant crack formed between $2 \%$ and $4 \%$ deformation due to the higher level of fracture energy as compared to Plt-5.02.3-1.7.

The contours of principal tensile strain in simulation Cyl-2.4-0.6-2.3 were the most unique in that three dominant cracks formed and there were multiple areas of tensile strain softening beginning at low deformation levels (i.e., less than 2\%). This high level of cracking is attributed to the low tensile strength used in the simulation and the high fracture energy level. These two properties prevented the opening of a dominant crack, and instead, allowed deformation to spread out over a longer portion of the member.

Deformation levels causing simulated reinforcement fracture are shown in Table 2, The various deformation levels reported for each simulation correspond to when the strain over the referenced gage length exceeds the fracture strain of $20 \%$. The predicted deformation capacity from the simulations using tensile properties from plate specimens (Plt-5.0-2.3-1.7 and 
Plt-3.6-3.4-2.4) were lower than those from the dogbone and cylinder specimens. The combined effects of high tensile strength and strain capacity resulted in the formation of more localized HPFRCC damage once a dominant crack formed. Upon formation of a dominant crack, the deformation shifts from the combination of HPFRCC and reinforcement to only the reinforcement which eventually leads to fracture of the reinforcing bars.

Therefore, these results suggest there is a a trade-off between higher strengths at low levels of deformation, and reduced component level deformation capacity between different material properties. Lower tensile strengths and strain capacities will reduce the contribution of the HPFRCC to the component strength, but will prevent localized cracks from forming at a dominant crack location.

It is interesting to note that simulated deformation capacity due to reinforcement fracture increased when tensile properties were selected from tensile specimens of larger cross section geometry. For example, the tensile specimen associated with Cyl-2.4-0.6-2.3 had the highest cross sectional area, and the highest simulated deformation capacity, while the tensile specimen associated with Plt-5.0-2.3-1.7 had the lowest deformation capacity and the lowest cross sectional area. This is likely due to the fact that thinner cross sections can cause fiber orientation predominantly in the direction of loading, resulting in higher tensile properties than larger cross sections. As shown here, high tensile strengths and strain capacities may have an adverse effect on component performance because reinforcement strains concentrate a dominant crack upon formation. These findings, however, are limited to the reinforcement ratio and conditions shown herein.

Table 2: Deformation levels causing fracture for various gage lengths.

\begin{tabular}{cccc}
\hline $\begin{array}{c}\text { Simulation } \\
\text { Name }\end{array}$ & $\begin{array}{c}\text { Predicted Deformation Capacity for Various Gage Lengths } \\
\text { 10 mm Gage Length }\end{array}$ & $\begin{array}{c}\text { 20 mm Gage Length } \\
\text { 30 mm Gage Length }\end{array}$ \\
\hline Plt-5.0-2.3-1.7 & $10.2 \%$ & $10.6 \%$ & $11.4 \%$ \\
Dgb-4.1-1.9-2.3 & $10.7 \%$ & $11.0 \%$ & $11.3 \%$ \\
Plt-3.6-3.4-2.4 & $10.5 \%$ & $10.8 \%$ & $11.2 \%$ \\
Cyl-2.4-0.6-2.3 & $11.5 \%$ & $11.8 \%$ & $12.4 \%$ \\
\hline
\end{tabular}

\section{SUMMARY}

Variations in tensile properties obtained from specimens of various sizes and geometries [17, [18] were studied by conducting numerical simulations on reinforced HPFRCC components. Computational simulation results were compared to experimental behavior of a reinforced HPFRCC component specimen tested to failure.

Results showed that when tensile properties from thin plate specimens were used to describe the HPFRCC tensile behavior, simulations overestimated component strength and underestimated deformation capacity. Tensile properties taken from larger specimens produced numerical simulation results that were more consistent with experimental performance in terms of deformation capacity and strength.

These results highlight the need for the development of a standard tensile test that can provide realistic tensile properties for simulation of reinforced components to high levels of deformation.

\section{ACKNOWLEDGMENTS}

All simulations were performed using the finite element software DIANA Release 10.0 The author gratefully acknowledges support from the John A. Reif, Jr. Department of Civil and Environmental Engineering and the Newark College of Engineering at New Jersey Institute of Technology. The author would like to thank Prof. Sarah L. Billington and Timothy Frank for their valuable input at the outset of this research.

\section{References}

[1] A.E. Naaman and H.W. Reinhardt. Proposed classification of hpfrc composites based on their tensile response. Materials and Structures, 39(5):547-555, 2006.

[2] S.L. Billington and J.K. Yoon. Cyclic Response of Unbonded Posttensioned Precast Columns with Ductile FiberReinforced Concrete. ASCE Journal of Bridge Engineering, 9(4):353-363, July 2004. 

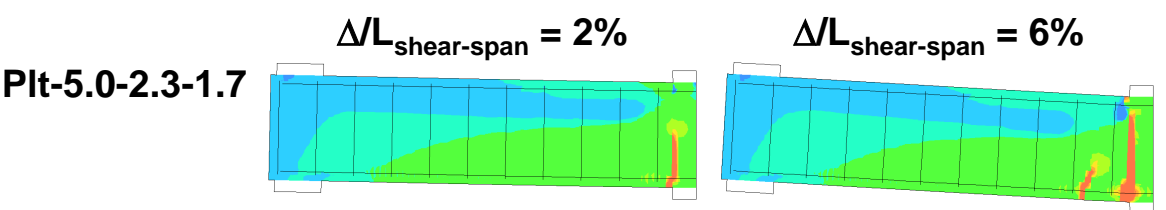

DOI 10.21012/FC9.189

Dgb-4.1-1.9-2.3
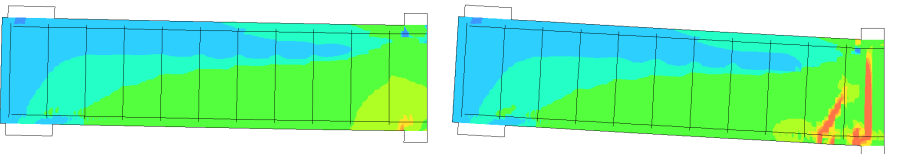

$\Delta / L_{\text {shear-span }}=12 \%$

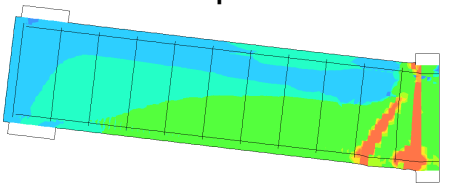

Plt-3.6-3.4-2.4
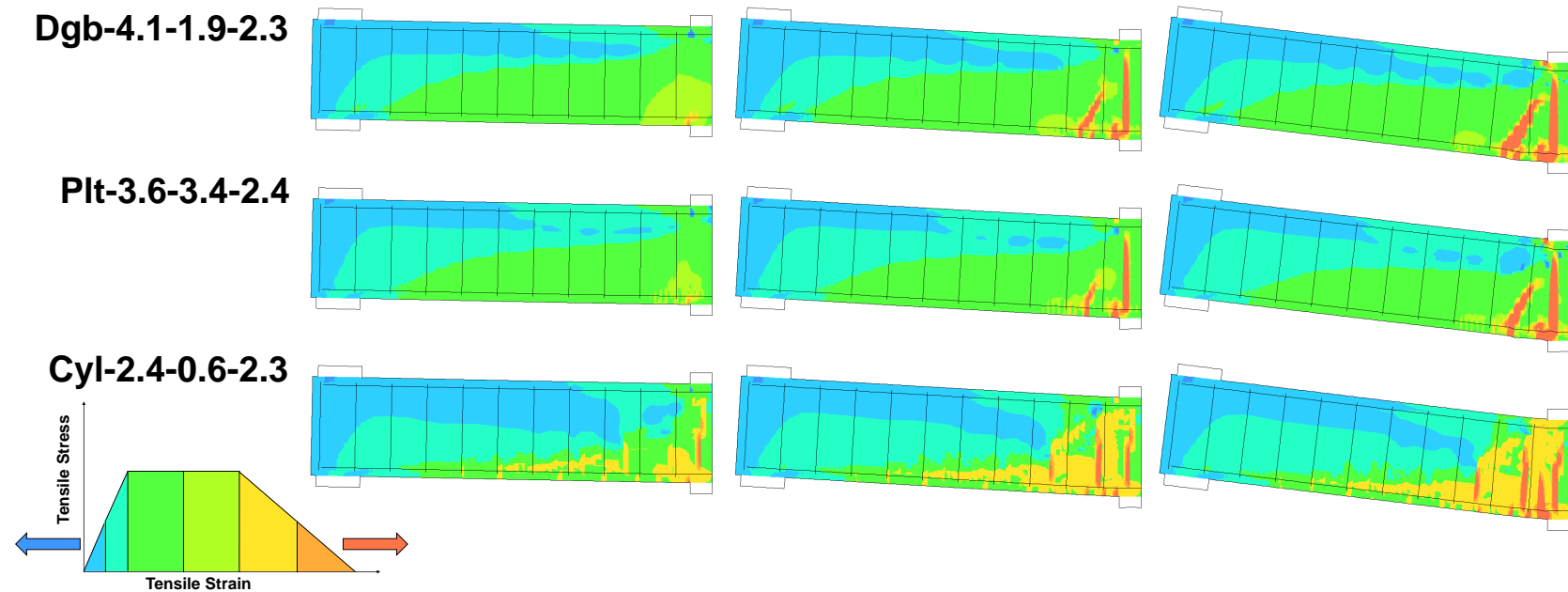

Figure 4: Contours of principal tensile strain at various deformation levels.
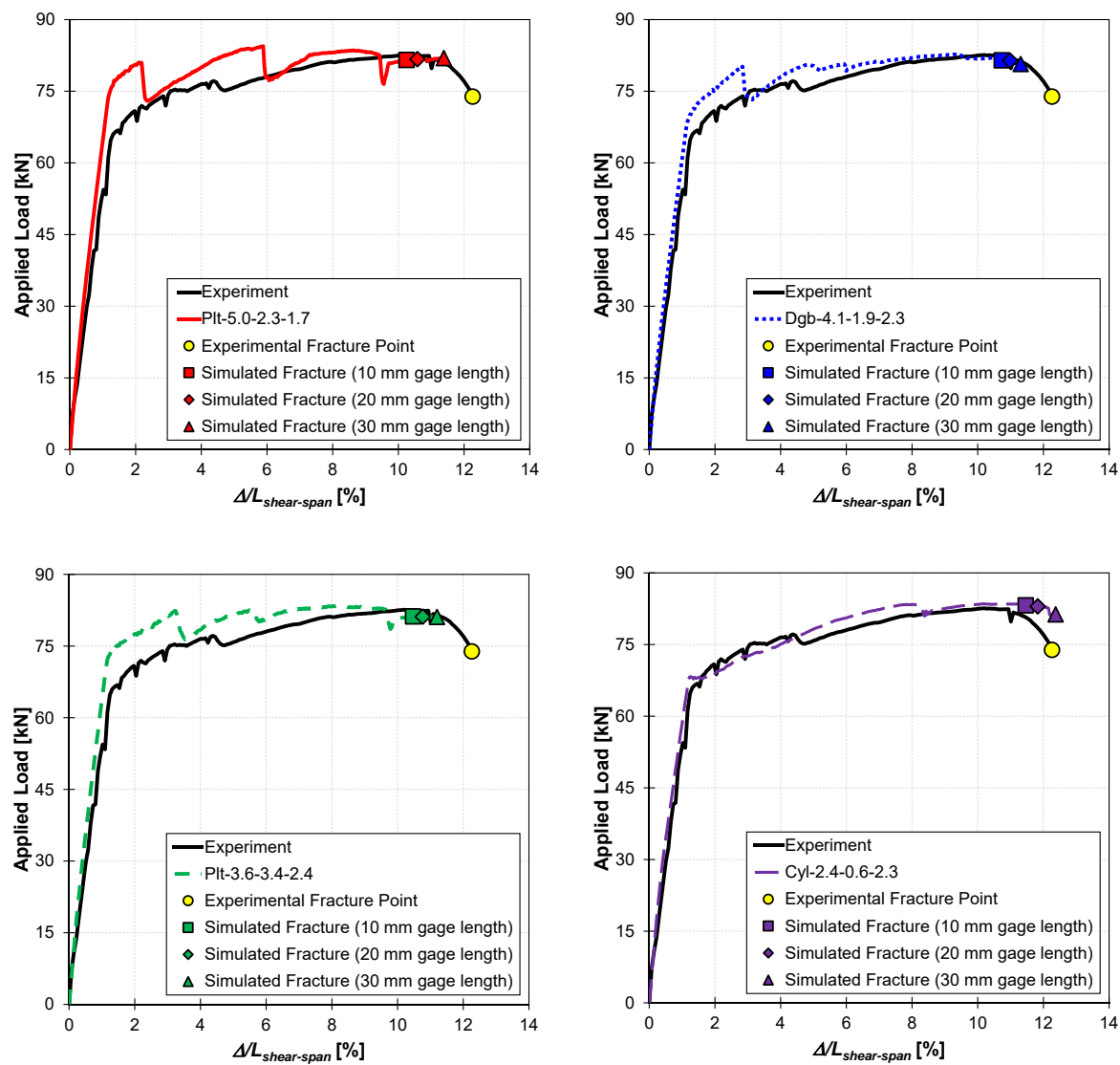

Figure 5: Full applied load versus deformation. 
[3] B.A. Canbolat, G.J. Parra-Montesinos, and J.K. Wight. Experimental study on seismic behavior of high-performance fiber-reinforced cement composite coupling beams. ACI Structural Journal, 102(1):159-166, 2005.

[4] G.J. Parra-Montesinos, S.W. Peterfreund, and S.H. Chao. Highly damagetolerant beam-column joints through use of high-performance fiber-reinforced cement composites. ACI Structural Journal, 102(3):487 - 495, 2005.

[5] G. Fischer and V.C. Li. Effect of matrix ductility on deformation behavior of steel reinforced ecc flexural members under reversed cyclic loading conditions. ACI Structural Journal, 99(6):781 - 790, 2002.

[6] R.D. Lequesne, G.J. Parra-Montesinos, and J.K. Wight. Seismic Behavior and Detailing of High-Performance FiberReinforced Concrete Coupling Beams and Coupled Wall Systems. Journal of Structural Engineering, 139(8):13621370, 2012.

[7] D.G. Lignos, D.M. Moreno, and S.L. Billington. Seismic Retrofit of Steel Moment-Resisting Frames with HighPerformance Fiber-Reinforced Concrete Infill Panels : Large-Scale Hybrid Simulation Experiments. Journal of Structural Engineering, 140(3):1-13, 2014.

[8] G.J. Parra-Montesinos and P. Chompreda. Deformation capacity and shear strength of fiber-reinforced cement composite flexural members subjected to displacement reversals. Journal of Structural Engineering, 133(3):421 - 431, 2007.

[9] M.J. Bandelt and S.L. Billington. Impact of reinforcement ratio and loading type on the deformation capacity of highperformance fiber-reinforced cementitious composites reinforced with mild steel.
DOI 10.21012/FC9.189 Journal of Structural Engineering, page 04016084, 2016.

[10] D.M. Moreno, W. Trono, G. Jen, C.P. Ostertag, and S.L. Billington. Tension stiffening in reinforced high performance fiber reinforced cement-based composites. Cement and Concrete Composites, 50(2014):36-46, 2014.

[11] S.H. Chao, A.E. Naaman, and G.J. ParraMontesinos. Bond behavior of reinforcing bars in tensile strain-hardening fiberreinforced cement composites. ACI Structural Journal, 106(6):897-906, 2009.

[12] M.J. Bandelt and S.L. Billington. Bond behavior of steel reinforcement in highperformance fiber-reinforced cementitious composite flexural members. Materials and Structures, 49(1):71-86, 2016.

[13] T.S. Han, P.H. Feenstra, and S.L. Billington. Simulation of highly ductile fiberreinforced cement-based composite components under cyclic loading. ACI Structural Journal, 100(6):749-757, 2003.

[14] P. Kabele. Multiscale framework for modeling of fracture in high performance fiber reinforced cementitious composites. Engineering Fracture Mechanics, 74(12):194-209, 2007.

[15] C.C. Hung and S. El-Tawil. Hybrid Rotating/Fixed-Crack Model for HighPerformance Fiber-Reinforced Cementitious Composites. ACI Materials Journal, 107(6):568-576, 2010.

[16] B. Gencturk and A.S. Elnashai. Numerical modeling and analysis of ECC structures. Materials and Structures, 2012.

[17] T. Kanakubo, K. Shimizu, M. Katagiri, T. Kanda, H. Fukuyama, and K. Rokugo. Tensile Characteristics Evaluation of DFRCC - Round Robin Test Results by JCI-TC. International RILEM Workshop on High Performance Fiber 
Reinforced Cementitious Composites in Structural Applications, (1):27-36, 2006.

[18] K.S. Douglas and S.L. Billington. Strain rate dependence of HPFRCC cylinders in monotonic tension. Materials and Structures, 44(1):391-404, July 2010.

[19] Peter H. Feenstra. Computational Aspects of Biaxial Stress in Plain and Reinforced
DOI 10.21012/FC9.189 Concrete. PhD thesis, Delft University of Technology, 1993.

[20] P.H. Feenstra, J.G. Rots, A. Arnesen, J.G. Teigen, and K.V. Hoiseth. A 3D constitutive model for concrete based on a conrotational concept. In De Borst, Bicanic, Mang, and Meschke, editors, Computational Modelling of Concrete Structures, Proceedings of EURO-C 1998, pages 1322, Rotterdam, 1998. Balkema. 